Article

\title{
Principles and Applications of the Global Human Settlement Layer as Baseline for the Land Use Efficiency Indicator-SDG 11.3.1
}

\author{
Michele Melchiorri ${ }^{1}$, Martino Pesaresi ${ }^{2}$, Aneta J. Florczyk ${ }^{2}\left(\mathbb{D}\right.$, Christina Corbane $^{2}(\mathbb{D}$ \\ and Thomas Kemper $2, *$ (D) \\ 1 Piksel S.r.l, Via E. Breda 176, 20126 Milano, Italy; michele.melchiorri@mail.polimi.it \\ 2 European Commission, Joint Research Centre (JRC), 21027 Ispra, Italy; martino.pesaresi@ec.europa.eu (M.P.); \\ aneta.florczyk@ec.europa.eu (A.J.F.); christina.corban@ec.europa.eu (C.C.) \\ * Correspondence: thomas.kemper@ec.europa.eu
}

Received: 31 August 2018; Accepted: 11 February 2019; Published: 18 February 2019

check for updates

\begin{abstract}
The Global Human Settlement Layer (GHSL) produces new global spatial information, evidence-based analytics describing the human presence on the planet that is based mainly on two quantitative factors: (i) the spatial distribution (density) of built-up structures and (ii) the spatial distribution (density) of resident people. Both of the factors are observed in the long-term temporal domain and per unit area, in order to support the analysis of the trends and indicators for monitoring the implementation of the 2030 Development Agenda and the related thematic agreements. The GHSL uses various input data, including global, multi-temporal archives of high-resolution satellite imagery, census data, and volunteered geographic information. In this paper, we present a global estimate for the Land Use Efficiency (LUE) indicator-SDG 11.3.1, for circa 10,000 urban centers, calculating the ratio of land consumption rate to population growth rate between 1990 and 2015. In addition, we analyze the characteristics of the GHSL information to demonstrate how the original frameworks of data (gridded GHSL data) and tools (GHSL tools suite), developed from Earth Observation and integrated with census information, could support Sustainable Development Goals monitoring. In particular, we demonstrate the potential of gridded, open and free, local yet globally consistent, multi-temporal data in filling the data gap for Sustainable Development Goal 11. The results of our research demonstrate that there is potential to raise SDG 11.3.1 from a Tier II classification (manifesting unavailability of data) to a Tier I, as GHSL provides a global baseline for the essential variables called by the SDG 11.3.1 metadata.
\end{abstract}

Keywords: SDG11; Land Use Efficiency; Open Data; GHSL; Landsat; urbanization; urban expansion; population mapping

\section{Introduction}

With the unanimous adoption of the United Nations (UN) General Assembly resolution 70/1 "Transforming our World: the 2030 Agenda for Sustainable Development", the Member States agreed upon a framework of 17 Sustainable Development Goals (SDG) to guide societal development. The action plan, building on the experience of the Millennium Development Goals, intertwines aspirational goals with an ambitious monitoring framework that is composed of 169 parameters in order to monitor progress made in meeting the SDGs. The capacity to monitor such progress is reported to be hampered by data gaps and entangled by the lack of statistical capacity to support the monitoring framework [1-4].

In this framework, a multi-level governance of information collection, reaching across intergovernmental institutions, national agencies, and civil society has evolved. The global partnership 
is coordinated by the UN Statistical Commission, with the mandate of implementing the indicator framework and the review of SDG and targets [3], the Inter-Agency Expert Group on SDG Indicators, the UN Statistical Division that hosts the Committee of Experts on Global Geospatial Information Management (UN-GGIM), and Non-Governmental Organizations. This latter major group of stakeholders includes the Group on Earth Observations and the Committee on Earth Observation Satellites, which work in promoting the integration of statistical, geospatial, and other big data in order to equip the SDG monitoring framework with the necessary data and making SDG reporting possible and as complete as possible. In order to map the capacity in monitoring SDG indicators, the Inter-Agency Expert Group on SDG Indicators developed a three-tier classification for the indicators. The classification criteria are based on the simultaneous availability of an internationally agreed methodology and standard to monitor the indicator, and the presence of data produced by countries covering at least half the countries and representing half of the population of a region. As a result of the $7^{\text {th }}$ Inter-Agency Expert Group on SDG Indicators meeting in spring 2018 (https:/ / unstats.un.org/sdgs/iaeg-sdgs/tier-classification/), 93 indicators are classified Tier I, 72 Tier II, and 62 Tier III. Alternative and innovative sources of data, especially derived from Earth Observation (EO), offer significant information, and especially data to support the SDG reporting [5-7].

Since the early XXI century, the human society is predominantly urban, as more than half of global population lives in cities [8]. In recognition of this trait of human development, the 2030 Development Agenda devoted a specific Goal to cities: SDG 11, which aims to "Make cities and human settlements inclusive, safe, resilient and sustainable". Despite that human nature is so intertwined with the urban condition [9], mankind is currently able to monitor less than half of the SDG 11 indicators for its own man-made artificial environment. Many SDG 11 indicators require fine scale local data that need to be sourced locally, which often result in inadequate data availability, especially in countries in transition and in data-poor territories.

EO have the capacity to make up for this information deficit, at a large scale, at high spatial resolution, repeatedly over time, and over wide geographical areas that serve multiple applications $[10,11]$, especially in the SDG framework $[6,12,13]$ or for generic urban development indicators [14].

In this contribution, we analyze the ways in which the above support can be enacted. In the paper, we analyze the principles and the architecture of the Global Human Settlement Layer (GHSL) and the application of GHSL to the SDG 11.3.1. The GHSL is a framework of data and tools that was developed from EO, census data, and volunteered geographic information that produces global maps of built-up areas, resident population, and settlement typologies for four epochs (1975, 1990, 2000, and 2015). GHSL layers have global coverage and they are released as open and free data. GHSL data and derived scientific information to inform policy decisions were released in 2016 at the Habitat III conference with the aim of supporting the 2030 Development Agenda and its thematic agreements (Sendai Framework for Disaster Risk Reduction, United Nations Framework Convention on Climate Change, and the New Urban Agenda). GHSL information is particularly salient in the contexts of disaster risk reduction, urbanization, and human settlement dynamics, where fine scale information on the presence of people and built-up areas are of high importance [15]. GHSL data served to quantify the process of urbanization [16], observe population density [17], over 40 years of human settlements development [18], and the exposure to natural hazards [19]. In this paper, the GHSL contributes to estimating SDG 11.3.1, which aims to measure the "ratio of land consumption rate to population growth rate". This indicator requires data on the spatial extent of the settlement and its population. Furthermore, information is needed with a fine scale level of detail, and it must be consistent across the world and over time in order to provide a comprehensive global overview. The article focuses on the Tier II nature of SDG 11.3.1, for which an agreed methodology exists. However, it is not implemented, as the necessary data are not yet established. With the use of GHSL data, we provide evidence to suggest that SDG 11.3.1 could be raised from its Tier II classification. 
First, we present the principles of the GHSL and its data layers; second, we explain how this information is used to feed the SDG 11.3.1 formulation. The results of data analysis present the process of spatial expansion and demographic change in urban centers across the globe between 1990 and 2015, the Land Use Efficiency (LUE) value of urban centers (LUE value or LUE is used in this research to indicate the ratio of land consumption rate to population growth rate-LCRPGR, as per the United Nations SDG 11.3.1 Metadata), and the change in built-up areas per capita by region of the world.

\section{Materials and Methods}

In Section 2.1, we briefly introduce the GHSL concept, its three geospatial layers that map built-up areas (GHS-BUILT), resident population (GHS-POP), and settlement typologies (GHS-SMOD). In Section 2.2, we present the methodology that was applied in this study to estimate SDG 11.3.1 according to the internationally agreed methodology.

\subsection{The Global Human Settlement Layer Principles}

The GHSL concept was introduced by the European Commission (EC), Joint Research Centre (JRC) during the years 2008-2011, in the frame of the program named "Information Support for Effective and Rapid External Action", developing new image information mining technologies that are in support of geo-spatial information analysis for global security and stability $[20,21]$. At that time, the application areas setting the requirements for the GHSL were framed inside the post-natural-disaster and post-conflict damage, needs and reconstruction assessment, including refugee camps and temporary, rapidly-changing human settlement monitoring [21-23]. In this frame, the notion of "built-up area" was introduced after a critical revision of the available satellite-derived land-use/land-cover information categories. $[24,25]$. The data and the semantic requirements of these initial application areas strongly influenced the design of the GHSL information production system. In particular, they were influencing the design of the automatic satellite image information mining methods that were outlined under a set of pragmatic principles, as summarized below:

- robustness against real-world Big Earth Data scenarios [26-28] involving large-volume, largely heterogeneous/unstructured data sources, and rapidly changing data specifications [29],

- enhanced semantic interoperability and robustness against multi-stakeholder international information decision support scenarios, and

- effectiveness in time-critical image-derived analytics requirements that are set by crisis management applications.

Early GHSL proof-of-concept was provided using European medium resolution ENVISAT ASAR data-Mapping Human Settlements Globally, European Union Science Hub News, 21/3/2011, an extensive global sample of image data that were collected from optical sensors ranging from 0.5 to 10 meters of spatial resolution [25], and a seamless pan-European image data layer at $2.5 \mathrm{~m}$ of spatial resolution in support to the European Cohesion policy [30]. During 2014, the process of applying the GHSL concept in support to post-2015 international frameworks was initialized. They included: the UN Third Conference on Housing and Sustainable Urban Development (Habitat III, 2016), the 2030 Agenda on sustainable development goals (SDGs), the UN Framework Convention on Climate Change, and the Sendai Framework for Disaster Risk Reduction (DRR) 2015-2030.

The setting of this new area of application introduced three new general requirements in the GHSL concept, aligned with the principles that were published in 2014 by the United Nations Secretary-General's Independent Expert Advisory Group on a Data Revolution for Sustainable Development (IEAG) [7]:

- operates in an open and free data and methods access policy (open input, open method, open output),

- facilitates reproducible, scientifically defendable, fine-scale, synoptic, complete, planetary-size, and cost-effective information production, and 
- facilitates information sharing and multilateral democratization of the information production and collective knowledge building.

The first and second requirements are linked to the need of public control of the data-driven policy decisions, and they are aligned to the Data Sharing Principles of the inter-ministerial Group of Earth Observation (GEO) and the Global Earth Observation System of Systems (GEOSS) [31]. The second and third requirements are necessary to process fine-scale global data, lowering the information production cost and thus enlarging the floor of the potential information producers, and consequently improving the inclusiveness and multi-laterality of the global information production ecosystem.

Nowadays, information is abundant, redundant, and also (in general) largely contradictory-typically not being harmonized. It is rapidly changing, heterogeneous, and only partially structured, because multilateral actors with a multiplicity of different objectives create it. According to [32], "Big data" are high-volume, high-velocity, and high-variety information assets that demand cost-effective, innovative forms of information processing for enhanced insight and decision making. In this scenario, the GHSL takes a pragmatic adaptive perspective. Artificial intelligence is used to find the relevant associations between different data streams at different level of abstraction/semantics and different scales with the minimal set possible of assumptions. In the new method that was proposed by the GHSL for the classification of remotely-sensed data [33], causal deterministic models are largely complemented by data-driven inductive inferential reasoning —analogously as argued by [34]. The whole data volume (samples =all) is typically used for making the inferences: this improves their reliability in noisy and unstructured information, and data environments where the assumptions needed for the correct sampling and stratification procedures are often largely violated or too expensive to be implemented. The GHSL methodological focus is provided on a computationally efficient search of associative rules between large comprehensive data series describing the whole universe $[29,33,35]$. This is in contrast to a computationally expensive search of laws explaining few carefully sampled points in the same data universe. In these (big, complex) data scenarios, the resilience (model transferability) of the eventually-found laws to new data segments that were recorded in the continuous information flux is considered to be generally low, consequently not paying-off the cost of their production.

The lack of Terminological Consistency, Semantic Consistency, and Cartographic Consistency of available land cover classification systems and land cover products that were generated from EO data at the global, national, and local scales are well known and related to the multilateralism of the observations that were made from different and not fully translatable perspectives, including different aims, methodology, and domain of the observers [36]. The above is emphasized by the rapid technological development of new EO sensors and new data classification paradigms, enlarging the spectrum of the possible EO-derived information content and cartographic specifications (scale, generalization). In order to face this abstraction complexity, the GHSL selects an "open-and-low-abstraction-level" methodological approach, improving the capacity of public discussion of the assumptions behind the GHSL-data-derived findings. The GHSL data categories are designed in a hierarchical abstraction schema allowing for the discussion of part of them without impacting the whole automatically generated categorical system. The rules translating input baseline data streams to GHSL information and high-level abstractions are open, humanly readable, and publicly discussable.

The repeatability of measurements refers to the ability to repeat measurements that were made regarding the same subject under identical conditions [37]. The measurements that were generated by the GHSL system are fully repeatable. The same input data and the same information extraction method produces identical numerical results. This is necessary to maintain full control of data, methods, and results lineages in the "Real-word (Big) Data Scenarios", as described above. A corollary of this principle is that GHSL avoids the use of Artificial Intelligence methods that are based on stochastic iterative optimization processes, such as Random Forest [38], Deep Learning [39], and similar frameworks. Such approaches may provide effective results under specific conditions (for example, 
under the condition of low levels of noise in the training set), but by definition they cannot be fully repeatable unless the initial set of arbitrary stochastic conditions (seeds) are saved and then re-used. The stochastic arbitrariness of these methods and their difficulty in generating a human-understandable set of decisional criteria (or classification rules) translating data streams into information make them difficult to apply to information support for public policies. This is especially evident in cases where prescriptive policies are involved. The data classification method must provide a univocal set of explicit rules that must be publicly controllable and make sense for the human impacted by these policy decisions [40].

\subsection{The GHSL Data Layers}

Since 2014, various pre-releases of the GHSL data were shared among the GEO partnership. The first public release of the GHSL was announced at the Habitat III conference of Quito, in October 2016. The data are freely accessible from the JRC Open Data Portal (https: / / data.jrc.ec.europa.eu/) and the GEOSS portal (http:/ / www.geoportal.org). Since 2017, the GHSL data and tools have been contributing to the GEO Human Planet Initiative, supporting the GEO Strategic Plan 2016-2025.

The GHSL suite contains three main grid-based layers (Table 1) covering four epochs: 1975-1990-2000-2015. GHS-BUILT [41] (Figure 1a) is an EO derived product, mapping built-up areas (density). The information is extracted from 40 years of Landsat imagery archives [42] through Symbolic Machine Learning workflows [25,33,43]. The process is based on a training set owning heterogeneous completeness (geographical and temporal coverage), thematic definitions, and reliability. The training set includes MERIS Globe Cover [44], LandScan population grids [45], Open Street Map, GeoNames, and MODIS 500 [46]. The result is a series of global maps of built-up areas in grid format for the four epochs in World Mollweide projection (EPSG: 54009):

- at $250 \mathrm{~m}$ resolution in which values are expressed as decimals from 0 to 1 (density);

- at $1 \mathrm{~km}$ resolution in which values are expressed as decimals from 0 to 1 (density); and,

- at $30 \mathrm{~m}$ resolution in Spherical Mercator (EPSG: 3857), a multi-temporal layer where the presence of built-up areas per epoch is classified in numbers ranging from 6 (built-up area mapped 1975) to 3 (built-up area mapped in 2015), with additional classes for the non-built-up land (2), presence of water (1), and no data (0).

Table 1. Synthesis and features of Global Human Settlement Layer (GHSL) data.

\begin{tabular}{|c|c|c|c|c|}
\hline Name & Semantic & Grid Resolution & Epoch ${ }^{1}$ & Main Input Data \\
\hline GHS-BUILT & $\begin{array}{l}\text { Density of built-up area } \\
\text { per grid cell }\end{array}$ & $30 \mathrm{~m}, 250 \mathrm{~m}, 1 \mathrm{~km}$ & 2015, & Satellite imagery \\
\hline GHS-POP & $\begin{array}{l}\text { Population counts per } \\
\text { grid cell }\end{array}$ & $250 \mathrm{~m}, 1 \mathrm{~km}$ & $\begin{array}{l}2000 \\
1990 \\
1975\end{array}$ & $\begin{array}{l}\text { Census data, } \\
\text { GHS-BUILT }\end{array}$ \\
\hline GHS-SMOD & $\begin{array}{l}\text { Classification of each grid } \\
\text { cell into one of the } \\
\text { Settlement Model classes: } \\
\text { high density cluster, low } \\
\text { density cluster, and rural } \\
\text { cells }\end{array}$ & $1-\mathrm{km}$ & & $\begin{array}{l}\text { GHS-BUILT, } \\
\text { GHS-POP }\end{array}$ \\
\hline
\end{tabular}

\footnotetext{
${ }^{1}$ Temporal dimension.
} 


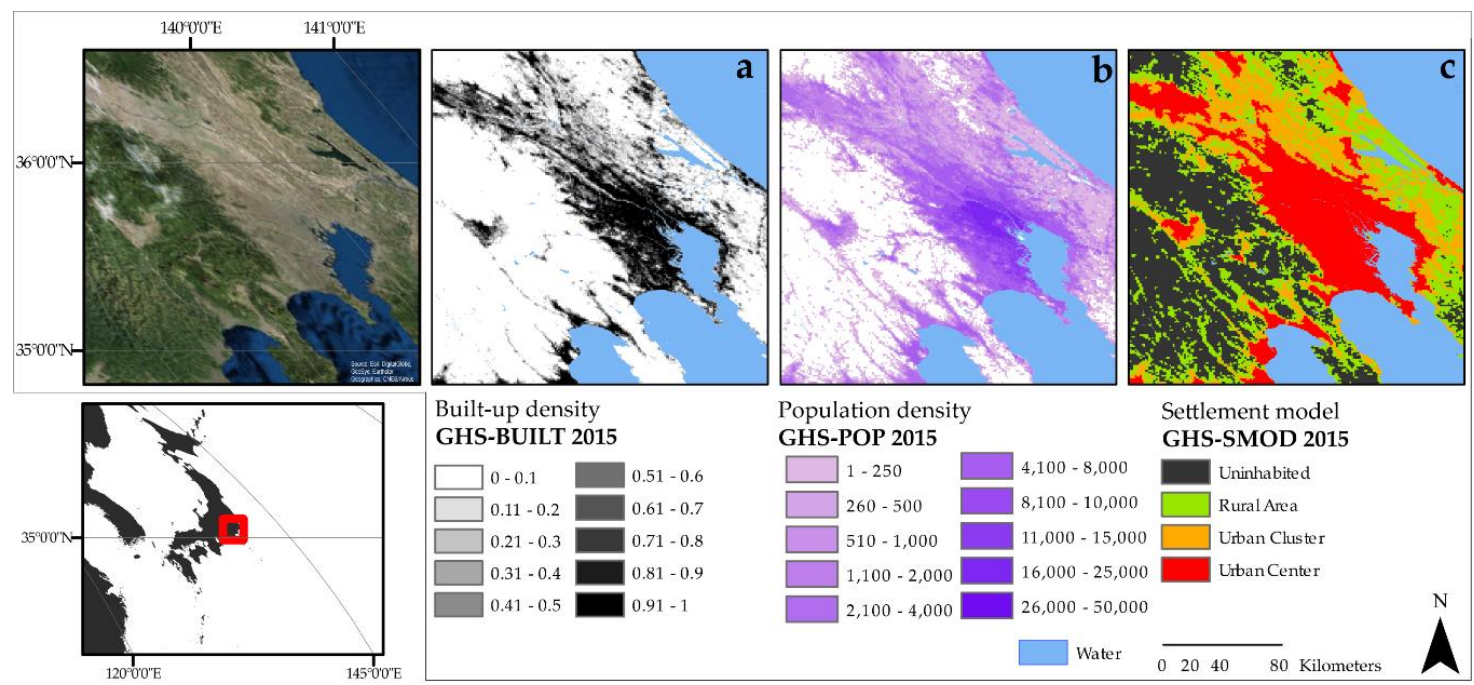

Figure 1. Example of GHSL data, three geospatial layers that map built-up areas (GHS-BUILT) (a), three geospatial layers that map resident population (GHS-POP) (b), three geospatial layers that map settlement typologies (GHS-SMOD), and (c) displayed at $1 \mathrm{~km}$ spatial resolution in the area of Tokyo (Japan) and compared to the imagery base map.

GHS-POP [47] maps the estimated resident population on the basis of built-up area presence (Figure 1b). They are based on CIESIN GPWv4 demographic data (derived from census or administrative units), and population is distributed using GHS-BUILT. GHS-POP is available at two resolutions for the four epochs in World Mollweide (EPSG: 54009):

- at $250 \mathrm{~m}$ resolution; and,

- $\quad$ at $1 \mathrm{~km}$ resolution.

In both layers, the value of each grid cell reports the absolute number of inhabitants in the cell (density, as float).

GHS-SMOD (Figure 1c) [48] combines GHS-BUILT and GHS-POP to represent the Degree of Urbanisation [49] in the GHSL environment. In the GHS-SMOD, grid cells are classified in three classes: Urban Centre, Urban Cluster, and Rural Area, according to population density and population thresholds (of individual cells and group of cells) [50]. GHS-SMOD is available at $1 \mathrm{~km}$ resolution for the four epochs, in World Mollweide (EPSG: 54009). In the layer, cells are classified as rural cells (1), urban cluster (2), and urban centers (3). Urban centers are the human settlements with more than 50,000 inhabitants. Urban centers are delineated according to the Degree of Urbanisation methodology-as group of cells of $1 \mathrm{~km}$ with population density $\left(1,500\right.$ inhabitants per $\left.\mathrm{km}^{2}\right)$, population size $(50,000$ people), and 50\% built-up areas density. The dataset that we built to conduct this study consists of circa 10,000 urban centers, delineated from the GHS-SMOD layer for the epoch 2015, and it is a precursor of the GHSL Urban Centre Database (GHS-UCDB).

In 2017, a revised image processing workflow was implemented in the JRC Earth Observation Data and Processing Platform (JEODPP) and then applied to the Landsat multi-temporal imagery collection. As a result, an updated version of the GHSL (GHS-BUILT, GHS-POP, and GHS-SMOD) [51] was released in the community of the GEO Human Planet Initiative and it has been tested in this study.

The GHSL framework serves multiple applications and analytics methods. GHSL baseline data, GHS-BUILT, and GHS-POP are especially used as exposure layers in the disaster risk reduction sector in support of emergency management services (i.e., Copernicus EMS) [52], alert systems [53], and risk management decision support indexes (i.e., INFORM) [54]. GHS-POP and GHS-SMOD were applied to estimate the carbon footprints of human settlements [55], travel time to major cities [56], and global patterns of human domination [57] and presence on the planet [18]. Through these applications, GHSL has become an established source supporting studies on the human interaction with and the 
modification of the environment over time. More importantly, the GHSL baseline data (GHS-BUILT, GHS-POP, and GHS-SMOD layers) can be injected in Sustainable Development Goals metadata to estimate SDG indicators. Below, we explore the use of GHSL to estimate the SDG 11.3.1.

Multi-Temporal and Spatial Harmonization of Information

GHSL layers are continuous global raster data, with information on the spatial footprint of settlements-built-up areas that are processed using Landsat imagery at corresponding epochs and a population that is modeled on the basis of the Gridded Population of the World (GPW). The information on built-up areas is extracted through the open workflow [43], and it is fed with multi-temporal imagery from Landsat at corresponding epochs [41,58]. Information on population is derived from GPW, which is a fine scale, spatially disaggregated layer that is produced from population and housing censuses from which estimates for past epochs are derived and made to be consistent with, and adjusted to, United Nations World Population Prospects [59]. The availability of consistent and harmonized data across the globe and epochs makes the analysis of long term process of human settlement changes (1975-2015) providing valuable tools for urban development analytics, including a new lens with which to observe global urbanization, possible [16].

\subsection{SDG 11.3.1 Methodology}

The methodology for SDG 11.3.1 is established and referenced in the SDG indicators Metadata Repository managed by UNDESA (https:/ / unstats.un.org/sdgs/metadata). SDG 11.3.1 is classified as a Tier II indicator (meaning that an indicator is conceptually clear and with a methodology for its monitoring, but for which data are not regularly produced or available). To perform our experiments, we applied the established methodology using GHSL as input data. LUE monitors the "Ratio of land consumption rate to population growth rate" and it is entrusted to quantify the sustainable land use in the face of urban expansion pressures [60], both demographic and economic [61]. To estimate LUE, it is first necessary to quantify the rate of land consumption (LCR) and the population growth rate (PGR) in a given spatial unit over a time span. The two rates (LCR and PGR) are computed, as follows:

$$
\mathrm{LCR}=\frac{\mathrm{LN}\left(\frac{\mathrm{Urb} b_{t+n}}{\mathrm{Urb} b_{t}}\right)}{\mathrm{y}} \quad \mathrm{PGR}=\frac{\mathrm{LN}\left(\frac{\mathrm{Pop}_{\mathrm{t}+\mathrm{n}}}{\mathrm{Pop}_{\mathrm{t}}}\right)}{\mathrm{y}}
$$

where LN is the Natural Logarithm, Urb $b_{t}$ and $\mathrm{Urb}_{t+n}$ is the total areal extent of the land consumed (extent of the human settlement—quantified as built-up areas) at the initial reference year ( $\mathrm{t}$ - in this study 1990), and at the final reference year ( $t+n$-in this study 2015), respectively, Pop $t$ and Pop $_{t+n}$ input the total population of the spatial unit at the initial reference year $(t)$ and at the final reference year $(t+n)$, respectively, and $y$ is the number of years between $t$ and $t+n$. The estimate of the ratio of land consumption rate to population growth rate (LUE) is obtained with:

$$
\mathrm{LUE}=\frac{\mathrm{LCR}}{\mathrm{PGR}}
$$

To complement LUE that is a dimensionless value with a spatially explicit metric, we also calculated the built-up areas per capita $\left(\mathrm{BpC}_{\mathrm{t}}\right.$ in 1990 and $\mathrm{BpC}_{\mathrm{t}+\mathrm{n}}$ in 2015-in Equation (3) below) per urban center in 1990 and 2015 and the corresponding change $\left(\mathrm{BpC}_{\mathrm{c}}\right.$ as in Equation (4)).

$$
\begin{gathered}
\mathrm{BpC}_{\mathrm{t}}=\frac{\mathrm{URB}_{\mathrm{t}}}{\mathrm{POP}_{\mathrm{t}}} \\
\mathrm{BpC}_{\mathrm{c}}=\frac{\left(\mathrm{BpC}_{\mathrm{t}+\mathrm{n}}-\mathrm{BpC}_{\mathrm{t}}\right)}{\mathrm{BpC}_{\mathrm{t}}}
\end{gathered}
$$




\subsection{Estimation of SDG 11.3.1 Using GHSL Baseline Data}

In this paper, the GHSL baseline data is used for assessing the LUE over the period 1990-2015 for all cities worldwide. This is implemented, as follows:

- GHS-SMOD is used to delineate the extent of cities worldwide, defined as the areas classified as urban centers in the GHS-SMOD in the 2015 layer,

- for each of the spatially delineated city boundaries, GHS-BUILT for the epochs of 1990 and 2015 are used to assess the land consumption (LCR) over a period of 25 years, and

- for each of the spatially delineated city boundaries, GHS-POP for the epochs 1990 and 2015 are used to derive the PGR over a period of 25 years.

To perform analyses by region of the world, urban centers received a geographical attribute representing their unique regional location (the aggregation of countries adopted is the one reported in the UN World Urbanization Prospects 2018 [62] on the basis of the Global Administrative Map -V2.8 (https://gadm.org/data.html). The extraction of statistics on built-up areas and population was implemented in a Geographic Information System environment (ArcGIS) through zonal statistics operations.

\section{Results}

The results of the analysis report about: (a) the extent and demographics of urban centers between 1990 and 2015 (in Section 3.1); (b) the development trajectory analyzed with the Land Use Efficiency indicator sourcing the LUE value at urban centers level (in Section 3.2); and, (c) the differentiation of built-up areas per capita across regions of the world clustering urban centers in classes of LUE value (in Section 3.3). LUE has been estimated in circa 10,000 urban centers, as defined in the GHS-SMOD.

\subsection{Spatial Expansion and Demographic Growth in Urban Centers}

According to GHSL data, urban centers account in 2015 for a population exceeding 3.53 billion people and their built-up areas extend over almost 295 thousand $\mathrm{km}^{2}$ (Figure 2a). In 25 years (1990-2015), urban centers built-up areas expanded by 30\% and the population increased by $44 \%$. Trajectories of growth follow clear regional dynamics (Figure 2b): the highest demographic change in size and absolute spatial expansion takes place in Asia (+637 million inhabitants and +35.7 thousand $\mathrm{km}^{2}$ ), while the most significant population growth has occurred in Africa (the population of urban centers has almost doubled).

The interdependence between spatial expansion and demographic change manifests itself in terms of change in population density in urban centers. Population density has globally increased by $11 \%$, moving from 10,800 inhabitants per $\mathrm{km}^{2}$ in 1990 to 12,000 inhabitants per $\mathrm{km}^{2}$ in 2015 . The most significant processes of densification took place in Africa $(+40 \%)$ and Oceania $(+36 \%)$. Population density is stable in Asia ( $+1 \%$ and equivalent to 17,000 inhabitants per $\mathrm{km}^{2}$ in 2015). A modest reduction in density took place in Europe (-6\% and 6,300 inhabitants per $\mathrm{km}^{2}$ in 2015) and a density increase occurred in Northern America $\left(+4 \%\right.$ and 2,500 inhabitants per $\left.\mathrm{km}^{2}\right)$ and Latin America and the Caribbean ( $+8 \%$ and 12,200 inhabitants per $\left.\mathrm{km}^{2}\right)$. 

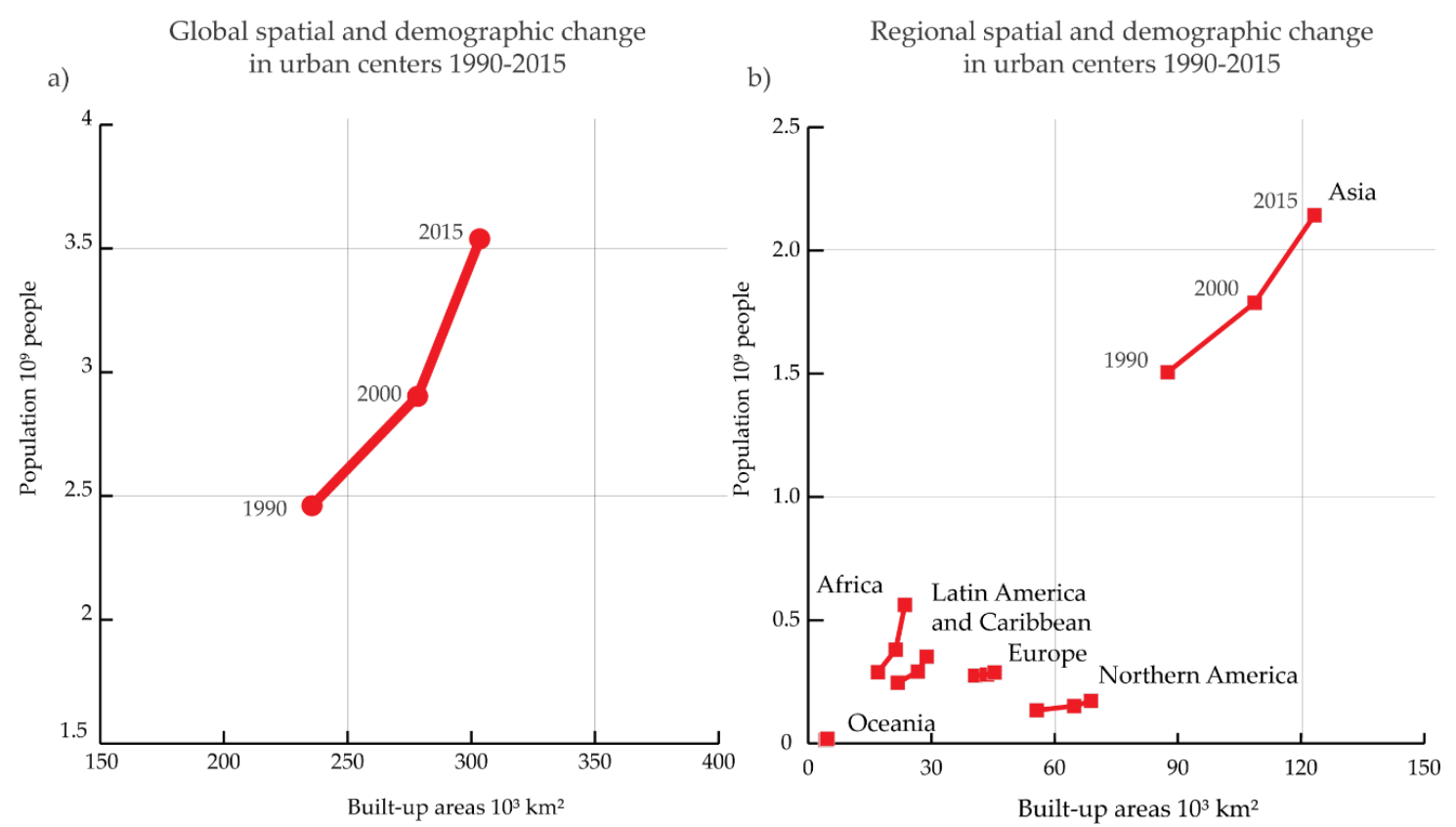

Figure 2. Multi-temporal global (a) and regional (b) extent of built-up areas and population in urban centers at corresponding epochs as estimated from GHSL data (GHS-POP and GHS-BUILT).

\subsection{LUE in 10,000 Urban Centers}

To synthetically report on the LUE trajectories of this vast dataset, we clustered the urban centers into five classes of LUE values: $\mathrm{LUE} \leq-1 ;-1<\mathrm{LUE} \leq 0 ; 0<\mathrm{LUE} \leq 1 ; 1<\mathrm{LUE} \leq 2$; LUE $>2$. This is to identify centers where demographic decline is simultaneous to spatial expansion $-1<$ LUE $\leq 0$ (and to substantial spatial expansion LUE $\leq-1)$, where population densification takes place $(0<$ LUE $\leq 1)$, and where the rate of spatial expansion is greater than the demographic growth $(1<$ LUE $\leq$ 2 ), and where spatial expansion takes place at a pace that is at least double the one of demographic growth (LUE $>2$ ).

Figure 3 below displays the geographical distribution of urban centers and their related LUE class (1990-2015). It emerges that 13\% of the centers in the world developed between 1990 and 2015, with a substantially negative LUE value $(<-1)$, particularly in countries in central and western Europe, central China, and south India. Values in the range of $-1<$ LUE $\leq 0$ are accounted for by $6 \%$ of urban centers of the world and this share reaches $21 \%$ in Europe (especially in eastern Europe and Russia), and $18 \%$ in Asia (mainly Japan). The most frequent LUE class across the world is that ranging $0<$ LUE $\leq 1$ ( $39 \%$ of the centers in the dataset). On a regional basis, this class represents $65 \%$ of the centers in Africa, more than half of the ones in Latin America and the Caribbean, 39\% the centers in Oceania, and almost $1 / 3$ of the ones in Asia and Europe. The class $1<$ LUE $\leq 2$ includes $20 \%$ of the centers in the world, but almost $1 / 3$ the ones in Latin America and the Caribbean, $\frac{1}{4}$ the ones in Northern America, and for $22 \%$ of the ones in Africa. The last class (LUE > 2) globally accounts for $22 \%$ of the centers; the share increases in Asia -31\%, especially including centers in India and northeast and south China. 


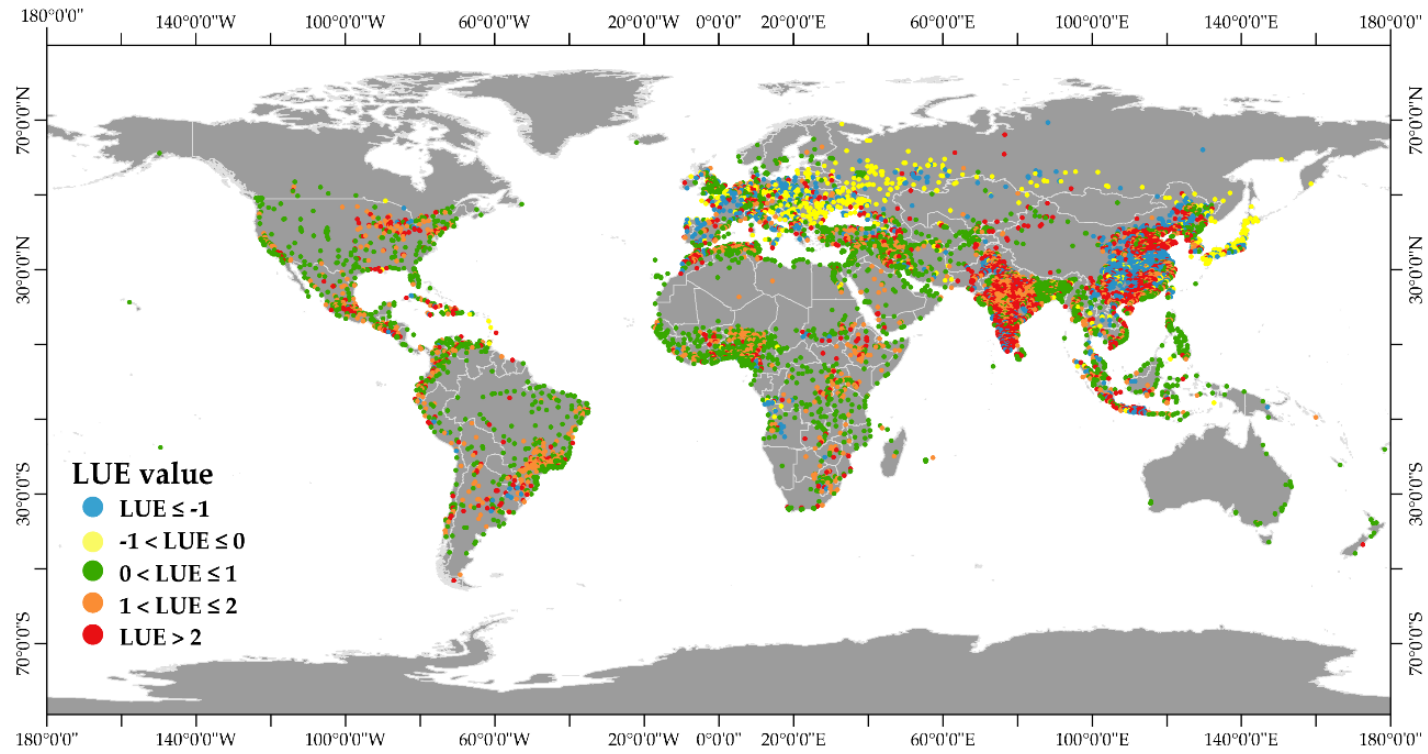

Figure 3. Comprehensive visualization of the Land Use Efficiency (LUE) value in circa 10,000 urban centers that were computed in the period 1990-2015.

\subsection{Built-Up Areas per Capita and Land Use Efficiency}

The LUE indicator (that is a dimensionless value) has been further characterized observing the built-up area per capita in the year $2015\left(\mathrm{BpC}_{\mathrm{t}+\mathrm{n}}\right)$ in the LUE classes that were considered in the previous section. This operation presents an example of the spatial implications of the LUE indicator (Figure 4). The following arguments are based on the average built-up areas per capita that were calculated for each of the 10,000 urban centers and then averaged by the regional collocation of the center. Results demonstrate that in continents like Europe and North America in the class of LUE > 2, in which spatial expansion takes place at a rate that is at least double that of population growth, the built-up areas per capita exceed, respectively, 180 and $490 \mathrm{~m}^{2}$ per inhabitant. Great variations are also observed in comparing the built-up area per capita in the same LUE class across regions. In the case of a development trajectory of population densification $(0<\mathrm{LUE}<1)$, the built-up areas per capita are almost $450 \mathrm{~m}^{2}$ per person in Northern America and $175 \mathrm{~m}^{2}$ per person in Europe. This drops by almost $50 \%$ in Latin America and the Caribbean ( $90 \mathrm{~m}^{2}$ per person), to almost $70 \mathrm{~m}^{2}$ per person in Asia, and to $52 \mathrm{~m}^{2}$ per person in centers in Africa.

In terms of average change of built-up areas per capita between 1990 and 2015, the values are also diverse. In the class $0<$ LUE $<1$, the built-up areas per capita shrink between $10 \%$ (in Europe) and $26 \%$ (in Africa). In the class of LUE $>2$, built-up areas per capita more than doubled in Latin America and the Caribbean, Asia, and Africa, increased by half in Northern America, by $15 \%$ in Europe, and by $6 \%$ in Oceania.

As a comprehensive overview of the SDG 11.3.1 quantified with GHSL data over the 25 years between 1990 and 2015, the results show that urban centers follow a development trajectory in which the rate of population growth prevailed over that of spatial expansion, with a LUE that is equivalent to 0.72. In absolute terms, the urban centers expanded globally over a land surface that is equivalent to almost $67,800 \mathrm{~km}^{2}$ (approximately the surface of Ireland) to settle about 1.1 billion new people (almost the population of India in 2015). 


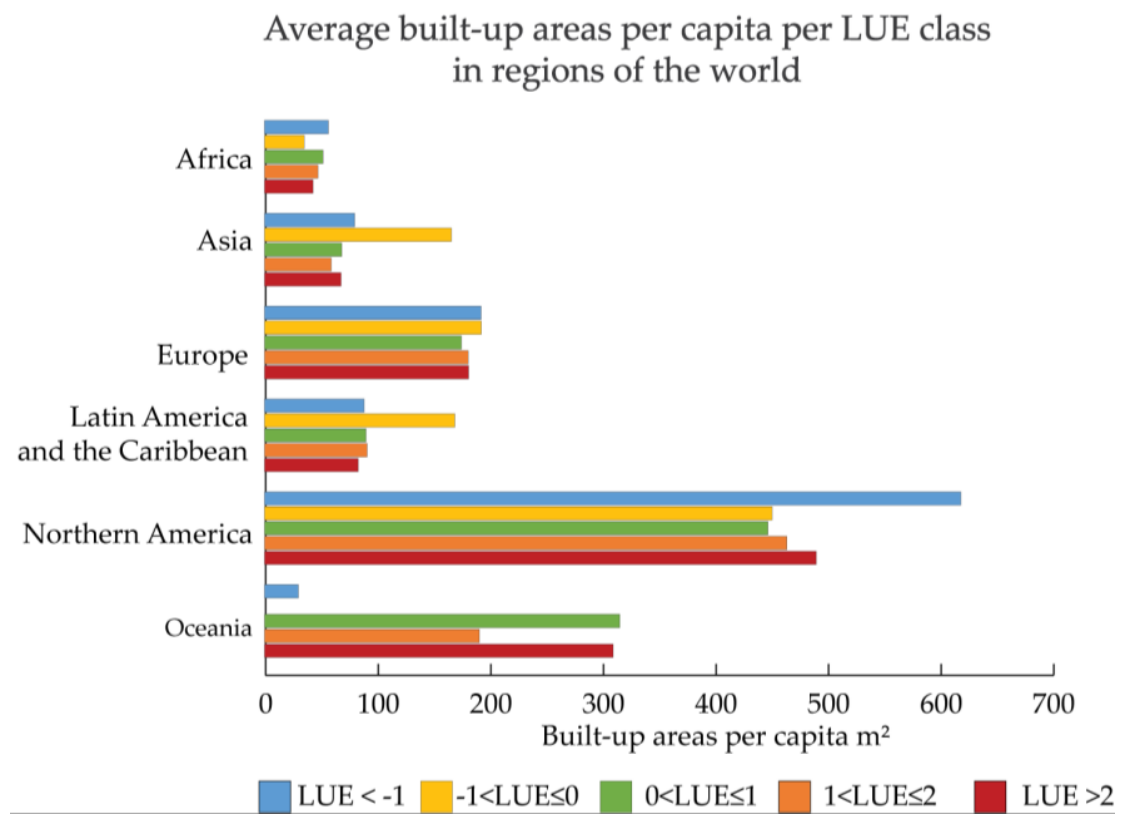

Figure 4. Regional comparison of built-up areas per capita.

\section{Discussion}

In the following section, we develop two main strands of arguments. One analyzes GHSL fitness for purpose of supporting SDG indicators and intergovernmental agreements with open data to fill the present gaps. In Section 4.1, we discuss the GHSL architecture and design features that enable an action-oriented support to SDG monitoring, in particular thanks to a full open and free data cycle (input data, methods, output/results) and the capacity to handle big-data scenarios by harmonizing data across space and time.

The other argument focuses on the implications of the empirical findings of this research in contributing to selected intergovernmental policy literature on urban development (Section 4.2).

\subsection{Open Data and Tools Filling Gaps of a Tier II Indicator}

The action oriented outcome of the GHSL framework architecture that was demonstrated by our results is that indicator 11.3.1 was estimated for the year 0 of the 2030 Development Agenda (2015) against 25 years of spatial and demographic change in urban centers.

In practice, using open and free data, it could be possible to raise SDG 11.3.1 from its Tier II status using the GHSL approach to fill the present data gap. With respect to UNDESA metadata, the GHSL operationalization of the SDG 11.3.1 estimation has been performed with two key premises. Firstly, the adoption of the Degree of Urbanisation people based "Global Harmonized Definition of Cities and Settlements" allowed for the delineation of the spatial units of analysis (the extent of urban centers in the epoch 2015). Secondly, LCR and PGR were defined, respectively, as the change in the built-up areas (from GHS-BUILT derived from Landsat) and in population (from GHS-POP) between epochs in these spatial units.

This is a pragmatic approach to implement the conceptual definition of "land consumption" intended as "the expansion of built-up area which can be directly measured" (SDG 11.3.1 metadata, p.2). This application was made possible by the GHSL principles and key characteristics:

- global geographical coverage;

- multi-temporal (diachronic) information;

- demographic and spatial (built-up areas) information;

- open and free data; and, 
- capacity to adapt to user requirements and hierarchical abstraction concepts.

In particular, the GHS-SMOD allowed for the identification of urban centers in a spatially consistent way (meeting the requirement of the stakeholders that are involved in the global commitment to develop a "harmonized definition of cities and settlements" - the European Union, the Organisation for Economic Co-operation and Development, the World Bank, and UN-Habitat), and to derive their population and built-up areas extent in a harmonized manner across epochs and areas of the world. This approach excludes forms of sampling, while it captures urban centers of any size greater than 50,000 inhabitants in 2015. Sampling methods to reduce the complexity of "real world big data scenarios" to limit the population of the dataset (the number of cities to ease information handling and production) may introduce aberrations and reveal patterns that are caused by the set of assumptions of the sampling methodology. Within the GHSL framework, the user is empowered to set its own user requirements (i.e., demographic criteria to define urban centers), replicate analyses, and information production.

Further to the above motives, the GHSL framework offers a suite of free tools, especially the MASADA (Massive Spatial Automatic Data Analytics), DUG (Degree of Urbanisation Grid), and LUE (Land Use Efficiency) tools. The MASADA Tool is developed to support the production of local and regional settlement layers by automatic classification of satellite imagery (both high and very high-resolution data). Using as a training set, land cover information or a coarse settlement map (to incorporate in the workflow radiometric, textural, and morphological features), a supervised classification of remotely sensed data (through SML classifier) extracts built-up area information. The tool is primarily devoted to the extraction of built-up areas with a preset of workflows for SPOT-5, SPOT-6/7, RapidEye, and CBERS-4, yet it can be applied to other imagery sources (i.e., GeoEye-1, WorldView-2/3, Pléiades, and Quickbird) to derive other land cover maps-provided that the appropriate training set is given in input. The second tool supporting the SDG estimate is dedicated to the delineation of urban areas, as defined in the Degree of Urbanisation definition [49]. Urban centers, urban clusters, and rural areas can be delineated using the DUG tool. The tool is designed to work with GHS-BUILT and GHS-POP, but other spatial and demographic layers could also be used. With this tool, the user is free to use proprietary data on built-up and population and to set ad hoc population criteria and threshold to define settlement typologies. The LUE Tool (a Qgis plugin) [63] enables the estimation of the SDG 11.3.1 in GIS environment with an input of spatial multi-temporal information on the spatial extent of the settlement and its demography at the corresponding epochs.

While this study proposes a comprehensive retrospective estimation of the LUE indicator across the globe, it is challenged by the input data being used.

- The definition of land consumption according to the GHSL data: in the GHSL concept and datasets, built-up areas that correspond to all man-made roofed constructions are used as proxies to Land Consumption. The latter, according to the UN definition, may be extended to cover other man-made features, such as roads, parking lots, or other artificial and impervious surfaces (and more closely align to SDG15.3.1);

- despite the use of increased spatial resolutions for built-up areas detection (as compared to precedent EO derived urban maps), some settlements can still be omitted due to their size or construction materials and some false detections may still be observed, especially over rocky bare lands; and,

- moreover, because the method for mapping built-up areas is based on physically observable built-up structures, as collected from satellite-borne sensors, some settlements could not be detected. Examples of invisible settlements as from the satellite remote sensing sensors that were adopted in this study include: small built-up structures below dense tree canopy, settlements carved in rock cliffs or underground, scattered huts in rural areas built with traditional materials, such as straw or clay (not distinguishable from the background soil and vegetation patterns), and some temporary settlements, such as tent refugee camps. 
In that context, the validation of built-up areas is essential for achieving a comprehensive and systematic description of the quality and validity of the GHSL built-up areas product. Continuous activities are performed in that direction in order to provide quality metrics that may allow for them to model, retro-fit, and compare the results that were obtained from the different GHSL products.

Despite these caveats, the GHSL suite of data and tools encompasses a wide spectrum of functionalities to support the SDG monitoring, both within its own resources (especially data), but also by offering free tools to users, empowering them to use third party or proprietary information sources, especially in the context of SDG 11.3.1. In particular, the GHSL architecture retains potential for the estimation of LUE to 2030. With the entry into service of the Sentinel-1 and Sentinel-2 constellations and the conception of workflows to process their data for built-up areas extraction in GHSL environment $[64,65]$ it is to foresee a community-based capacity to periodically update LCR estimates for the entire Earth.

\subsection{EO Derived Information on Human Settlements}

In recent times, the remote sensing and EO technology to acquire, process, and manage data has significantly improved. In particular, significant advances to the instruments to acquire information from space have taken place. The spatial resolution of new sensors has increased, as has temporal revisit time. Early EO derived products to map the extent of human settlement relied on coarse resolution imagery (MODIS or Landsat 1-3 MSS) or on a combination of the latter and nighttime lights (i.e., DMSP/OLS).

Although EO-based methods of settlement information extraction have helped in expanding the scientific understanding of human presence on the planet $[16,60,66,67]$, the lack of extensive validation and training sets covering multiple epochs and diverse geographical areas may limit accuracy assessments. The GHSL data have been validated in order to assess both the built-up areas detection (GHS-BUILT) [68,69] and the population map [70]. The results of the validation demonstrate that GHSL is one of the most reliable global, open, and free data, with the layer accuracy increasing over time and growing with development intensity. Albeit that GHS-BUILT and GHS-POP provide multi-temporal information mapping the extent and resident population of human settlements around the globe and representing a substantial improvement when compared to earlier EO derived products [46], recent satellites are expected to significantly improve this information. For example, the use of Sentinel 1 (GHS BUILT-UP Sentinel-1 Grid) as a training set for the Landsat, as implemented in [51], has enhanced the global delineation of human settlements from 40 years of Landsat satellite data archives.

Recent platforms equipped high-resolution (i.e., Sentinel-2) and very-high-resolution optical (i.e., SPOT) or synthetic-aperture radar technology (i.e., TerraSAR-X and Sentinel-1) proved to be effective in delivering maps of human settlements [30,64,65,71].

This new generation of information support researchers and policymakers in the understanding of the new geographies of human settlements in the era of a predominantly urban society. In particular, the finer spatial resolution of sensors contribute to the improvement of the detection of small roofed surfaces and urban features extraction [72], reducing omission and commission errors [64,73], and improving settlement mapping in territories subject to intense and fast transformations (especially in Africa and Asia).

The SDG 11.3.1 methodology requires globally comparable information to analyze the interdependence between spatial expansion of settlements and their demographic changes. Most of the existing geospatial data does not possess the characteristics that are necessary to estimate SDG 11.3.1 These are: (1) multi-temporal/diachronic information with global coverage; (2) demographic (PGR) and spatial (LCR) information; (3) harmonized urban-rural classification of settlements (to delineate areas of interests); and, (4) open and free data with open input, process, and output to fully support public policy. 
Our research findings support rationales on urbanization that allege that urban areas are efficient in terms of use of land resources [74], and that urban development is highly unequal across regions of the world [75]. Estimating a LUE < 1 corresponding to 25 years of urban development (1990-2015), we empirically illustrate that the rate of demographic growth in urban centers has exceeded the growth in space. Although GHS-BUILT does not account for the vertical dimension of built-up areas, this value could validate a dense/compact pattern of development that implies population densification, the diversity of LUE values across regions of the world, and the corresponding built-up areas per capita may reinforce the signals of widening urban divide, in terms of inequality in development. In particular, the comparison of built-up areas per capita in 2015 broken down into LUE classes and regions of the world manifests the traits of unfairness. When considering the least efficient LUE class (LUE > 2), built-up areas per capita in urban centers in Northern America are 10 times that in centers in Africa. Similar patterns are also found in the other LUE classes. This fact implies that substantially heterogeneous patterns of development can be captured by comparable- even the same-LUE values. By formulation, the LUE indicator does not retain a spatially explicit nature (dimensionless), yet it could be a proxy for a spatial and demographic trajectory of change. The Land Use Efficiency estimates seem to suggest that several territories encountering extensive population growth (i.e., Sub-Saharan Africa and South-East Asia) develop with LUE values that are between 0 and 1, corresponding to population densification, while negative LUE values (LUE $<-1$ ) is frequent in countries with low-or even negative-population growth rates (i.e., Eastern Europe, Japan, and some converging regions of the European Union).

\section{Conclusions}

In this article, we provide a concrete example of the contribution of Earth Observation and innovative geospatially derived data in support of the Sustainable Development Goals. The SDGs were negotiated in parallel to a comprehensive and ambitious monitoring framework. This framework is currently hampered by shortcomings in data availability and the statistical capacity for monitoring it, with only 93 indicators with a Tier I classification. Earth Observations set out as a key source of information to service SDG monitoring: by improving the availability of required data, supplying suitable and accurate data that cover long time series, and having wide/planetary geographical scope are compatible/complimentary with traditional statistical methods.

To provide a practical application of this service, we estimated, at the global level, Land Use Efficiency (SDG indicator 11.3.1), which is currently classified as a Tier II indicator due to the presence of an internationally agreed methodology, but in the absence of data. The GHSL provides the necessary data, harmonized in space and time, on the spatial distribution of built-up areas (GHS-BUILT), population (GHS-POP), and settlement typologies (GHS-SMOD), fulfilling the UNDESA metadata requirements for the indicator. In addition to the above, we also discussed the principles and architecture of the Global Human Settlement Layer that by design embraces an open input, open method, open output policy, has a modular hierarchical structure of information, tests and applies real-word (big) data scenarios, produces evidence based output analytics, and facilitates the repeatability of results. In particular, we emphasize the role of multi-temporal and spatial harmonization of information to enable comparative studies and analyses on development trajectories.

The quantitative results of the experimental application of GHSL data in support of the SDG indicator 11.3.1 show that urban centers developed between 1990 and 2015 with an LUE that was equivalent to 0.72 , whereas the rate of population growth has been greater than that of spatial expansion. In absolute terms, urban centers expanded over the terrestrial land surface to almost $67,800 \mathrm{~km}^{2}$ (approximately the area of Ireland) to settle almost 1.1 billion new people (almost the population of India in 2015). To further characterize LUE, we compared the built-up areas per capita in the epoch 2015 achieved in centers that developed in common LUE classes in various regions of the world. It emerges that there might be inequalities in the trajectories of development of centers that develop with comparable LUE values, but are located in different geographical areas. This is perceived, in 
particular, in comparing the changes in built-up areas per capita between 1990 and 2015. With the estimate of the LUE, we enacted UNGGIM instruction to test GHSL for the purpose. In this context, we reaffirm that, while GHSL data could support data-poor territories, they could also back data-rich parties for harmonization and comparison purposes. Our research concludes that the GHSL framework, with its tools and data, enables users to generate built-up area layers that can be used directly with UNDESA compiled demographic data to quantify LUE. New satellites (Sentinel constellation) are sources of information to map built-up areas for recent years and for the future with a higher resolution when compared to the open and free platforms of the past. The workflows that were generated in the open and free GHSL environment to map built-up areas, including the MASADA tool, could support the estimation of the Land Consumption Rate to 2030 with open data and open tools.

Author Contributions: Melchiorri and Martino Pesaresi; Data curation, Aneta J. Florczyk and Christina Corbane; Formal analysis, Michele Melchiorri and Aneta J. Florczyk; Funding acquisition, Thomas Kemper; Methodology, Michele Melchiorri, Martino Pesaresi and Christina Corbane; Project administration, Thomas Kemper; Software, Aneta J. Florczyk; Supervision, Martino Pesaresi and Thomas Kemper; Validation, Aneta J. Florczyk, Christina Corbane and Thomas Kemper; Writing-original draft, Michele Melchiorri and Martino Pesaresi; Writing-review \& editing, Michele Melchiorri, Martino Pesaresi, Aneta J. Florczyk, Christina Corbane and Thomas Kemper.

Funding: This work has been carried out in the frame of the institutional work program of the Joint Research Centre (JRC, European Commission) and supported by the administrative arrangement No. 33994 between the JRC and the Directorate General for Regional and Urban Policies (DG REGIO, European Commission).

Acknowledgments: The authors wish to recognize the support of Alan Steel for language editing. Authors are also thankful to Dr. Marcello Schiavina, who presented early results of this study at the International Conference on Sustainable Development 2018.

Conflicts of Interest: The authors declare no conflict of interest.

\section{References}

1. United Nations General Assembly. Transforming Our World: The 2030 Agenda for Sustainable Development A/RES/70/1; United Nations: New York, NY, USA, 2015.

2. Data for Development a Needs Assessment for SDG Monitoring and Statistical Capacity Development; United Nations Sustainable Development Solutions Network: Paris, France; New York, NY, USA, 2015.

3. Work of the Statistical Commission Pertaining to the 2030 Agenda for Sustainable Development A/RES/71/313; United Nations General Assembly: New York, NY, USA, 2017.

4. United Nations Statistical Commission. Contribution to the 2018 HLPF-United Nations Statistical Commission; United Nations Statistical Commission: New York, NY, USA, 2018.

5. Anderson, K.; Ryan, B.; Sonntag, W.; Kavvada, A.; Friedl, L. Earth observation in service of the 2030 Agenda for Sustainable Development. Geo-Spat. Inf. Sci. 2017, 20, 77-96. [CrossRef]

6. Paganini, M.; Petiteville, I. Satellite Earth Observations in Support of the Sustainable Development Goals, Special 2018 ed.; CEOS-ESA: Paris, France, 2018.

7. UN Secretary-General's Independent Expert and Advisory Group on the Data Revolution for Sustainable Development. A World that Counts Mobilising the Data Revolution for Sustainable Development; United Nations: New York, NY, USA, 2014.

8. UNDESA. World Urbanization Prospects the 2007 Revision; United Nations: New York, NY, USA, 2008.

9. Wirth, L. Urbanism as a Way of Life. Am. J. Sociol. 1938, 44, 1-24. [CrossRef]

10. Donaldson, D.; Storeygard, A. The View from Above: Applications of Satellite Data in Economics. J. Econ. Perspect. 2016, 30, 171-198. [CrossRef]

11. Zell, E.; Huff, A.K.; Carpenter, A.T.; Friedl, L.A. A User-Driven Approach to Determining Critical Earth Observation Priorities for Societal Benefit. IEEE J. Sel. Top. Appl. Earth Obs. Remote Sens. 2012, 5, 1594-1602. [CrossRef]

12. Earth Observations in Supports of the 2030 Agenda for Sustainable Development; Japan Aerospace Exploration Agency: Tokyo, Japan, 2017.

13. Noort, M. Earth Observation and Sustainable Development Goals in the Netherlands towards More Synergetic Use of Earth Observation: An exploratory Study; Ministry of Foreign Affairs of the Netherlands: The Hague, The Netherlands, 2017. 
14. Chrysoulakis, N.; Feigenwinter, C.; Triantakonstantis, D.; Penyevskiy, I.; Tal, A.; Parlow, E.; Fleishman, G.; Düzgün, S.; Esch, T.; Marconcini, M. A Conceptual List of Indicators for Urban Planning and Management Based on Earth Observation. ISPRS Int. J. Geo-Inf. 2014, 3, 980-1002. [CrossRef]

15. Chmutina, K.; Bosher, L. Rapid Urbanisation and Security: Holistic Approach to Enhancing Security of Urban Spaces. In The Palgrave Handbook of Security, Risk and Intelligence; Dover, R., Dylan, H., Goodman, M.S., Eds.; Palgrave Macmillan: London, UK, 2017; pp. 27-45.

16. Melchiorri, M.; Florczyk, A.; Freire, S.; Schiavina, M.; Pesaresi, M.; Kemper, T. Unveiling 25 Years of Planetary Urbanization with Remote Sensing: Perspectives from the Global Human Settlement Layer. Remote Sens. 2018, 10, 768. [CrossRef]

17. Smith, D.A. Visualising world population density as an interactive multi-scale map using the global human settlement population layer. J. Maps 2017, 13, 117-123. [CrossRef]

18. Pesaresi, M.; Melchiorri, M.; Siragusa, A.; Kemper, T. Atlas of the Human Planet 2016. Mapping Human Presence on Earth with the Global Human Settlement Layer; EUR 28116 EN; Publications Office of the European Union: Luxembourg, 2016.

19. Ehrlich, D.; Melchiorri, M.; Florczyk, A.J.; Pesaresi, M.; Kemper, T.; Corbane, C.; Freire, S.; Schiavina, M.; Siragusa, A. Remote Sensing Derived Built-Up Area and Population Density to Quantify Global Exposure to Five Natural Hazards over Time. Remote Sens. 2018, 10, 1378. [CrossRef]

20. Halkia, S.; Buda, D.; European Commission, Joint Research Centre, and Institute for the Protection and the Security of the Citizen. Information Support for Effective and Rapid External Action (ISFEREA) Support to External Security Unit; Publications Office of the European Union: Luxembourg, 2007.

21. Jasani, B.; Pesaresi, M.; Schneiderbauer, S.; Zeug, G. (Eds.) Remote Sensing from Space-Supporting International Peace and Security; Springer: Berlin/Heidelberg, Germany, 2009.

22. Pesaresi, M.; Ehrlich, D.; Ferri, S.; Florczyk, A.; Freire, S.; Haag, F.; Halkia, M.; Julea, A.M.; Kemper, T.; Soille, P. Global Human Settlement Analysis for Disaster Risk Reduction. Int. Arch. Photogramm. Remote Sens. Spat. Inf. Sci. 2015, 40, 837-843. [CrossRef]

23. Corbane, C.; Kemper, T.; Freire, S.; Louvrier, C.; Pesarasi, M. Monitoring the Syrian Humanitarian Crisis with the JRC's Global Human Settlement Layer and Night-Time Satellite Data; Publications Office of the European Union: Luxembourg, 2016.

24. Pesaresi, M.; Ehrlich, D. A methodology to quantify built-up structures from optical $\{$ VHR $\}$ imagery. In Global Mapping of Human Settlement Experiences, Datasets, and Prospects; Gamba, P., Herold, M., Eds.; CRC Press: Boca Raton, FL, USA, 2009; pp. 27-58.

25. Pesaresi, M.; Huadong, G.; Blaes, X.; Ehrlich, D.; Ferri, S.; Gueguen, L.; Halkia, M.; Kauffmann, M.; Kemper, T.; Lu, L.; et al. A Global Human Settlement Layer from Optical HR/VHR RS Data: Concept and First Results. IEEE J. Sel. Top. Appl. Earth Obs. Remote Sens. 2013, 6, 2102-2131. [CrossRef]

26. Baumann, P.; Mazzetti, P.; Ungar, J.; Barbera, R.; Barboni, D.; Beccati, A.; Bigagli, L.; Boldrini, E.; Bruno, R.; Calanducci, A.; et al. Big data analytics for Earth Sciences: The EarthServer approach. Int. J. Digit. Earth 2016, 9, 3-29. [CrossRef]

27. Nativi, S.; Mazzetti, P.; Santoro, M.; Papeschi, F.; Craglia, M.; Ochiai, O. Big Data challenges in building the Global Earth Observation System of Systems. Environ. Model. Softw. 2015, 68, 1-26. [CrossRef]

28. Guo, H. Big Earth data: A new frontier in Earth and information sciences. Big Earth Data 2017, 1, 4-20. [CrossRef]

29. Pesaresi, M. Global Fine-Scale Information Layers: The Need of a Paradigm Shift. In Proceedings of the Conference on Big Data from Space (BiDS'14), ESA-ESRIN, Frascati, Italy, 12-14 November 2014; Volume EUR 26868 EN, pp. 8-11.

30. Florczyk, A.J.; Ferri, S.; Syrris, V.; Kemper, T.; Halkia, M.; Soille, P.; Pesaresi, M. A New European Settlement Map From Optical Remotely Sensed Data. IEEE J. Sel. Top. Appl. Earth Obs. Remote Sens. 2016, 9, 1978-1992.

31. Doldirina, C. Open Data and Earth Observations: The Case of Opening Up Access to and Use of Earth Observation Data Through the Global Earth Observation System of Systems. J. Intellect. Prop. Inf. Tech. E-Commer. Law 2015, 6, 73-85.

32. Demchenko, Y.; de Laat, C.; Membrey, P. Defining architecture components of the Big Data Ecosystem. In Proceedings of the 2014 International Conference on Collaboration Technologies and Systems (CTS), Minneapolis, MN, USA, 19-23 May 2014; pp. 104-112. 
33. Pesaresi, M.; Syrris, V.; Julea, A. A New Method for Earth Observation Data Analytics Based on Symbolic Machine Learning. Remote Sens. 2016, 8, 399. [CrossRef]

34. Mayer-Schönberger, V.; Cukier, K. Big Data: A Revolution That Will Transform How We Live, Work, and Think; Houghton Mifflin Harcourt: Boston, MA, USA, 2013.

35. Pesaresi, M.; Syrris, V.; Julea, A. Benchmarking of the Symbolic Machine Learning Classifier with State of the Art Image Classification Methods_Application to Remote Sensing Imagery; JRC Technical Report EUR 27518; Publications Office of the European Union: Luxembourg, 2015.

36. Yang, H.; Li, S.; Chen, J.; Zhang, X.; Xu, S. The Standardization and Harmonization of Land Cover Classification Systems towards Harmonized Datasets: A Review. ISPRS Int. J. Geo-Inf. 2017, 6, 154. [CrossRef]

37. Taylor, B.; Kuyatt, C. Guidelines for Evaluating and Expressing the Uncertainty of NIST Measurement Results; National Institute for Standards and Technology: Gaithersburg, MD, USA, 2007.

38. Ho, T.K. Random decision forests. In Proceedings of the 3rd International Conference on Document Analysis and Recognition, Montreal, QC, Canada, 14-16 August 1995; Volume 1, pp. 278-282.

39. Zhong, S.; Liu, Y.; Liu, Y. Bilinear deep learning for image classification. In Proceedings of the 19th ACM international conference on Multimedia-MM'11, Scottsdale, AZ, USA, 28 November-1 December 2011; p. 343.

40. Colclough, C. Ethical artificial intelligence-10 Essential ingredients. Available online: https://www.oecdforum.org/users/75928-dr-christina-j-colclough/posts/29527-10-principles-for-ethical-artificial-intelligence (accessed on 16 February 2019).

41. JRC. GHS BUILT-UP Grid, Multitemporal 1975-1990-2000-2015; JRC Data Catalogue; European Commission, Joint Research Centre: Brussels, Belgium, 2015.

42. Gutman, G.; Huang, C.; Chander, G.; Noojipady, P.; Masek, J. Assessment of the NASA-USGS Global Land Survey (GLS) datasets. Remote Sens. Environ. 2013, 134, 249-265. [CrossRef]

43. Pesaresi, M.; Ehrlich, D.; Ferri, S.; Florczyk, A.; Freire, S.; Halkia, M.; Julea, A.; Kemper, T.; Soille, P.; Syrris, V. Operating Procedure for the Production of the Global Human Settlement Layer from Landsat Data of the Epochs 1975, 1990, 2000, and 2014; JRC Technical Report EUR 27741 EN; Publications Office of the European Union: Ispra, Italy, 2016.

44. Arino, O.; Perez, J.J.R.; Kalogirou, V.; Bontemps, S.; Defourny, P.; van Bogaert, E. Global Land Cover Map for 2009 (GlobCover 2009); PANGAEA—Data Publisher for Earth \& Environmental Science, 2012. Available online: https:/ / doi.pangaea.de/10.1594/PANGAEA.787668 (accessed on 16 February 2019).

45. Bhaduri, B.; Bright, E.; Coleman, P.; Dobson, J. LandScan: Locating people is what matters. Geoinformatics 2002, 5, 34-37.

46. Schneider, A.; Friedl, M.A.; Potere, D. A new map of global urban extent from MODIS satellite data. Environ. Res. Lett. 2009, 4, 044003. [CrossRef]

47. JRC; CIESIN. GHS Population Grid, Derived from GPW4, Multi-Temporal (1975, 1990, 2000, 2015); JRC Data Catalogue; European Commission, Joint Research Centre: Brussels, Belgium, 2015.

48. JRC. GHS Settlement Grid Multi-Temporal (1975, 1990, 2000, 2014); Joint Research Centre: Brussels, Belgium, 2015.

49. Dijkstra, L.; Poelman, H. A Harmonised Definition of Cities and Rural Areas: The New Degree of Urbanization; Publications Office of the European Union: Luxembourg, 2014.

50. Pesaresi, M.; Freire, S. GHS Settlement Grid Following the REGIO Model 2014 in Application to GHSL Landsat and CIESIN GPW v4-Multitemporal (1975-1990-2000-2015); JRC Data Catalogue; European Commission, Joint Research Centre: Brussels, Belgium, 2016.

51. Florczyk, A.; Ehrlich, D.; Corbane, C.; Freire, S.; Kemper, T.; Melchiorri, M.; Pesaresi, M.; Politis, P.; Schiavina, M.; Zanchetta, L. Community pre-Release of GHS Data Package (GHS CR2018) in support to the GEO Human Planet Initiative Version 1.0; Publications Office of the European Union: Luxembourg, 2018.

52. Freire, S.; Florczyk, A.; Ehrlich, D.; Pesaresi, M. Remote sensing derived continental high resolution built-up and population geoinformation for crisis management. In Proceedings of the 2015 IEEE International Geoscience and Remote Sensing Symposium (IGARSS), Milan, Italy, 26-31 July 2015; pp. 2677-2679.

53. Florczyk, A.; Andredakis, I.; Freire, S.; Ferri, S.; Pesaresi, M. Remote Sensing datasets supporting disaster alert systems on multiscale via Web services. In Proceedings of the 2015 IEEE International Geoscience and Remote Sensing Symposium (IGARSS), Milan, Italy, 26-31 July 2015. 
54. Ferrer, M.M.; Vernaccini, L.; Poljansek, K. Index for Risk Management_INFORM. Concept and Methodology Version 2017; EUR 28655 EN; Publications Office of the European Union: Luxembourg, 2017.

55. Moran, D.; Kanemoto, K.; Jiborn, M.; Wood, R.; Többen, J.; Seto, K.C. Carbon footprints of 13000 cities. Environ. Res. Lett. 2018, 13, 064041. [CrossRef]

56. Weiss, D.J.; Nelson, A.; Gibson, H.S.; Temperley, W.; Peedell, S.; Lieber, A.; Hancher, M.; Poyart, E.; Belchior, S.; Fullman, N.; et al. A global map of travel time to cities to assess inequalities in accessibility in 2015. Nature 2018, 553, 333-336. [CrossRef]

57. Cherlet, M.; Hutchinson, C.; Reynolds, J.; Hill, J.; Sommer, S.; von Maltitz, G. World Atlas of Desertification; Publications Office of the European Union: Luxembourg, 2018.

58. JRC. GHSL Data Packages Instructions for Data Access. V1.0; Joint Research Centre: Brussels, Belgium, 2016.

59. Center for International Earth Science Information Network-CIESIN-Columbia University. Gridded Population of the World, Version 4 (GPWv4): Population Density; NASA Socioeconomic Data and Applications Center (SEDAC): Palisades, NY, USA, 2016.

60. Schneider, A.; Woodcock, C.E. Compact, Dispersed, Fragmented, Extensive? A Comparison of Urban Growth in Twenty-five Global Cities using Remotely Sensed Data, Pattern Metrics and Census Information. Urban Stud. 2008, 45, 659-692. [CrossRef]

61. Venables, A.J. Breaking into tradables: Urban form and urban function in a developing city. J. Urban Econ. 2017, 98, 88-97. [CrossRef]

62. United Nations, Department of Economic and Social Affairs, Population Division. World Urbanization Prospects: The 2018 Revision; United Nations: New York, NY, USA, 2018.

63. Corbane, C.; Politis, P.; Pesaresi, M.; Kemper, T.; Siragusa, A. Estimation of Land Use Efficiency from the Global Human Settlement Layer (GHSL). In QGIS and Applications in Territorial Planning; Baghdadi, N., Mallet, C., Zribi, M., Eds.; John Wiley \& Sons, Inc.: Hoboken, NJ, USA, 2018; pp. 39-52.

64. Pesaresi, M.; Corbane, C.; Julea, A.; Florczyk, A.J.; Syrris, V.; Soille, P. Assessment of the Added-Value of Sentinel-2 for Detecting Built-up Areas. Remote Sens. 2016, 8, 299. [CrossRef]

65. Corbane, C.; Lemoine, G.; Pesaresi, M.; Kemper, T.; Sabo, F.; Ferri, S.; Syrris, V. Enhanced automatic detection of human settlements using Sentinel-1 interferometric coherence. Int. J. Remote Sens. 2018, 39, 842-853. [CrossRef]

66. Dou, Y.; Liu, Z.; He, C.; Yue, H. Urban Land Extraction Using VIIRS Nighttime Light Data: An Evaluation of Three Popular Methods. Remote Sens. 2017, 9, 175. [CrossRef]

67. Angel, S.; Blei, A.M.; Civco, D.M.; Lamson-Hall, P.; Parent, J.; Sanchez, N.G.; Thom, K. Atlas of Urban Expansion, 2015 ed.; The NYU Urbanization Project: New York, NY, USA; The Lincoln Institute of Land Policy: Cambridge MA, USA; UN Habitat: Nairobi, Kenya, 2015.

68. Leyk, S.; Uhl, J.H.; Balk, D.; Jones, B. Assessing the accuracy of multi-temporal built-up land layers across rural-urban trajectories in the United States. Remote Sens. Environ. 2018, 204, 898-917. [CrossRef]

69. Klotz, M.; Kemper, T.; Geiß, C.; Esch, T.; Taubenböck, H. Mapping spatial settlement patterns on a global scale: Multi-scale cross-comparison of new and existing global urban maps. Remote Sens. Environ. 2015, 178, 191-212. [CrossRef]

70. Freire, S.; Doxsey-Whitfield, E.; MacManus, K.; Mills, J.; Pesaresi, M. Development of new open and free multi-temporal global population grids at $250 \mathrm{~m}$ resolution. In Proceedings of the AGILE 2016, Helsinki, Finland, 14-17 June 2016.

71. Esch, T.; Heldens, W.; Hirner, A. The Global Urban Footprint. In Urban Remote Sensing, 2nd ed.; CRC Press: Boca Raton, FL, USA, 2018; pp. 3-14.

72. Weng, Q.; Quattrochi, D.A.; Gamba, P. (Eds.) Urban Remote Sensing, 2nd ed.; CRC Press: Boca Raton, FL, USA, 2018.

73. Yuan, J.; Chowdhury, P.K.R.; McKee, J.; Yang, H.L.; Weaver, J.; Bhaduri, B. Exploiting deep learning and volunteered geographic information for mapping buildings in Kano, Nigeria. Sci. Data 2018, 5, 180217. [CrossRef]

74. OECD. Compact City Policies; OECD Publishing: Paris, France, 2012. 
75. World Cities Report 2016 Urbanization and Development: Emerging Futures; United Nations Human Settlements Programme (UN-Habitat): Nairobi, Kenya, 2016; Volume HS/005/17E.

76. Florczyk, A.J.; Ferri, S.; Syrris, V.; Kemper, T.; Halkia, M.; Soille, P.; Pesaresi, M. A New European Settlement Map From Optical Remotely Sensed Data. IEEE J. Sel. Top. Appl. Earth Obs. Remote Sens. 2016, 9, 1978-1992.

(c) 2019 by the authors. Licensee MDPI, Basel, Switzerland. This article is an open access article distributed under the terms and conditions of the Creative Commons Attribution (CC BY) license (http://creativecommons.org/licenses/by/4.0/). 